\title{
Congenital Urinary Tract Anomalies: About Cases 80 Cases at the University Hospital of Brazzaville
}

\author{
Anani Wencesl Séverin Odzébé1,2* , Crayne Mboutol Mandavo ${ }^{1,3}$, Irene Patricia Lucie Ondimaa, \\ Prosper Alain Bouya ${ }^{1,2}$
}

${ }^{1}$ Faculty of Health Sciences, Marien Ngouabi University, Brazzaville, Congo

${ }^{2}$ Department of Urology-Andrology, University Hospital of Brazzaville, Brazzaville, Congo

${ }^{3}$ Department of Pediatric Surgery, University Hospital of Brazzaville, Brazzaville, Congo

Email: *odzebe_s@yahoo.fr

How to cite this paper: Odzébé, A.W.S., Mandavo, C.M., Ondima, I.P.L. and Bouya, P.A. (2020) Congenital Urinary Tract Anomalies: About Cases 80 Cases at the University Hospital of Brazzaville. Open Journal of Urology, 10, 8-15.

https://doi.org/10.4236/oju.2020.101002

Received: September 16, 2019

Accepted: December 27, 2019

Published: December 30, 2019

Copyright $\odot 2020$ by author(s) and Scientific Research Publishing Inc. This work is licensed under the Creative Commons Attribution International License (CC BY 4.0).

http://creativecommons.org/licenses/by/4.0/

\section{(c) (i) Open Access}

\begin{abstract}
Objective: To determine the diagnostic and therapeutic aspects of urinary tract anomalies in children in our environment. Patients and methods: This was a retrospective descriptive study conducted in the pediatric surgery and urology-andrology departments of the University Hospital of Brazzaville, from January 2012 to December 2017. Children aged 0 to 17 years old hospitalized for a malformation of the urinary tract were included. Results: The frequency of urinary tract anomalies was $1 \%$ of all patients admitted during the study period. The average age of the patients was 6.1 years (range, $0-17$ years). The most common motive of consultation was ectopic urethral meatus (66.2\%), vesical urine retention (18.7\%) and lumbar spine pain (6.3\%). Hypospadias was more common with $58.7 \%$, followed by posterior urethral valves (20\%), uretero-pelvic junction obstruction (7.5\%). The most frequent preoperative complications were urinary tract infection (11.3\%), urolithiasis $(3.7 \%)$ and renal failure (2.5\%). The treatment was surgical including urethroplasty (70.1\%), or instrumental based on destruction of valves (16.9\%). Conclusion: Urinary tract anomalies suffer late diagnosis and treatment in our practice. An antenatal screening strategy should be put in place to improve care to prevent the occurrence of complications.
\end{abstract}

\section{Keywords}

Malformations, Urinary Tract, Children, Brazzaville

\section{Introduction}

Congenital malformations of the urinary system are abnormalities of anatomical 
structures, external or internal, isolated or multiple, fixed or progressive, due to a disorder of embryogenesis [1], interesting both the kidneys and excretory ways. They occupy the 3rd rank of overall congenital anomalies with $10 \%$ of cases [2] and affect about $3 \%$ to $4 \%$ of the population [1]. The nature of anomalies is variable and their severity is different, ranging from complex anomaly to a simple anomaly of position or conformation [3]. While in Europe, malformative uropathies are diagnosed during antenatal examination [4] [5]; however in Africa, they are still diagnosed after birth, most often following a complication [6], the most feared being renal failure. In Congo, very few studies have been carried out on these pathologies [7] [8]; the objective of this study was the diagnostic and therapeutic aspects of UTA in children in our hospital practice environment.

\section{Patients and Methods}

This was a retrospective study that took place in the departments of Pediatric Surgery and Urology-Andrology of the University Hospital of Brazzaville from January 2012 to December 2017 (6 years). During the study period, we included all children from 0 to 17 years hospitalised for malformative uropathy operated or not, and having an exploitable medical data. The data collected on a survey form, from medical records and registers of admissions and operative procedure reporting. We studied the variables:

- epidemiological: frequency, sex, age;

- diagnostics:

- Clinical: motive of consultation, physical examination, discharge diagnosis, as well as the associated congenital anomalies.

- Paraclinical: renal and urinary tract ultrasonography, retrograde urethrocystography (RUC), intravenous urography (IVU) to determine the type of malformative uropathy and its repercussions; as well as serum creatinine and uroculture for complications.

- therapeutic: the radical treatment was either instrumental (bladder catheterization, destruction of valves with Béniqués sound) or surgical (urethroplasty, nephrectomy, pyeloplasty, ureterovesical reimplantation, bladder reconstruction);

- evolutionary: length of hospitalization, inpatient post-operative follow-up, the notion of death.

Analysis of data was done using the Epi Info software. Quantitative variables were expressed in terms of means \pm standard deviation and qualitative variables as percentage form. For the statistical analysis, we used the Pearson correlation test (chi-square) with a significance threshold $\mathrm{p}<0.005$.

\section{Results}

\subsection{Epidemiological Aspects}

During the study period, 8113 patients were admitted to the pediatric surgery and urology-andrology departments, including 80 UTA cases (1\%). The average 
age was $6.1 \pm 4.6$ years old $(0-17$ years old). There was a male predominance with 76 boys and 4 girls.

\subsection{Diagnostic Aspects}

Clinically, the circumstances of discovery were: ectopic urethral meatus in 53 cases (66.2\%), vesical urine retention and dysuria in 15 cases (18.7\%), lumbar spine pain in 5 cases (6.3\%), urinary incontinence in 4 cases (5.0\%), female external genitalia abnormality in 2 cases (2.5\%) and abdominal bloating in 1 case (1.3\%).

Ultrasound of the urinary tract (Table 1) was performed in 24 children (30\%), RUC in 24 (30\%) and IVU in 8 (10\%). Ultrasonography revealed bilateral ureterohydronephrosis and fight bladder in 13 cases (54.2\%), hydronephrosis with cortical thinning in 3 cases $(21.1 \%)$. In 4 cases (16.4\%), ultrasound findings were normal.

\section{Diagnoses}

The discharge diagnoses are shown in Table 2.

Hypospadias was the most common disease with 47 cases (58.7\%) and the average age at the time of diagnosis was 5.6 years old ( 0 - 17 years old).

\section{Associated malformations}

Five children $(6.3 \%)$ had other congenital conditions associated with UTA. Symphyseal disjunction occurred in 2 children with bladder exstrophy, bifid clitoris in 2 children, and anorectal malformation with vaginal hypoplasia in one child.

\section{Complications at the time of diagnosis}

The main complications found were urinary tract infection in 9 children (4 E. coli, 3 Klebsiella and 2 Candida albicans infections), bladder stones in 3 children and renal failure in 2 children (serum creatinine 50 and $58 \mathrm{mg} / \mathrm{L}$ ).

\subsection{Therapeutic Aspects}

Seventy-seven (96.2\%) patients were treated including two patients with renal cystic dysplasia who were monitored and one patient died before surgery. Surgical treatment was performed in 62 cases $(81.2 \%)$ depending on the disease; and $15(17.5 \%)$ patients had instrumental treatment by destruction of the posterior urethral valves either by laminating or with Beniqué probe. The different types of surgeries performed are shown in Table 3.

Table 1. Ultrasound findings.

\begin{tabular}{|c|c|c|}
\hline Ultrasound findings & Number & $\%$ \\
\hline $\begin{array}{l}\text { Bilateral uretero-hydronephrosis } \\
\text { and fight bladder }\end{array}$ & 13 & 54.2 \\
\hline $\begin{array}{l}\text { Hydronephrosis with } \\
\text { thinning of the cortex }\end{array}$ & 5 & 21.1 \\
\hline Renal cyst & 2 & 8.5 \\
\hline normal & 4 & 16.4 \\
\hline Total & 24 & 100 \\
\hline
\end{tabular}


Table 2. Distribution of patients according to discharge diagnoses.

\begin{tabular}{ccc}
\hline Discharge diagnoses & N & $\%$ \\
\hline Hypospadias & 47 & 58.7 \\
Posterior urethral valves & 16 & 20 \\
Pyelo-ureteral junction syndrome & 6 & 7.5 \\
Bladder exstrophy & 4 & 5.0 \\
Epispadias & 3 & 3.7 \\
Cystic dysplasia & 2 & 2.5 \\
Ectopia of the ureteral meatus & 1 & 1.3 \\
Vesicoureteral reflux & 1 & 1.3 \\
Total & $\mathbf{8 0}$ & 100
\end{tabular}

Table 3. Distribution of the workforce by type of surgery.

\begin{tabular}{ccc}
\hline Type of surgery & Number & $\%$ \\
\hline Urethroplasty & 50 & 64.9 \\
Resection of posterior urethral valves & 12 & 15.6 \\
Pyeloplasty & 6 & 7.8 \\
Bladder plasty & 4 & 5.2 \\
Urethrostomy & 2 & 2.6 \\
Right nephrostomy & 1 & 1.3 \\
Right nephrectomy & 1 & 1.3 \\
Uretero-vesical reimplantation & 1 & 1.3 \\
Total & 77 & 100
\end{tabular}

${ }^{\star}$ For hypospadias or epispadias repair.

\subsection{Evolutionary Aspects}

The mean length of hospitalization was 13.7 days \pm 8.6 days ( 3 to 45 days).

The postoperative follow-up of patients was appreciated during hospitalization. Fifty-five $(68.7 \%)$ patients had simple postoperative follow-up. Twenty patients $(42.5 \%)$ who had surgery for hypospadias had fistula in the postoperative follow-up. Two (1.3\%) patients had vesico-parietal fistula after bladder repair for bladder exstrophy, and we noted a case of severe sepsis (1.3\%).

A 6-year-old patient with chronic renal failure with a bilateral mute kidney at the IVU complicating posterior urethral valves, died before the operation.

\section{Discussion}

As with any retrospective, descriptive and monocentric hospital study, we were limited in the collection of some data on the one hand and the results obtained cannot be extrapolated in general. 


\subsection{Epidemiological Aspects}

In our study, UTA represent $1 \%$ of all admissions to the service. This frequency is lower than those observed in Conakry [9] with 4\%. For Kahloul et al. [10], this rate is $3 \%$, in a study conducted in a pediatric ward where admissions are higher than ours. Most authors agree that uropathies are frequent in boys like observed in our study [9] [10] [11]; it cans be explained by the high frequency of malformations of the male urethra, especially hypospadias and epispadias.

The average age of children in our study is 6.1 years old ( 0 to 17 years old) at the time of diagnosis. This result is close to that reported by Asinobi et al. [6] in Nigeria while in western countries postnatal discovery is earlier, particularly with an average age of 11 months in Germany [12], 10.6 months in Poland [13]. This diagnostic delay in our hospital practice + can be explained by the virtual absence of antenatal diagnosis on the one hand and by socio-cultural reasons on the other. While in developed countries, the antenatal screening rate for UTA is $60 \%$ to $70 \%$ [5] [14] from a routine obstetrical ultrasound; which allows early management of patients.

\subsection{Diagnostics Aspects}

\section{Circumstances of discovery}

The majority of patients (66.2\%) were admitted for external urologic malformation, including urethral meatus position abnormality, anterior abdominal wall defect, others for clinical manifestations such as dysuria or acute retention of urine, abdominal and/or lumbar pain, abdominal mass with lumbar contact. While others have been discovered by complications: urinary tract infection (11.2\%), urolithiasis (3.7\%), or even renal failure (2.5\%). Urinary tract infection is the most commonly reported circumstance in the literature [2] [10]; indeed, the occurrence of urine infection which that is the age remains a mode of revelation very frequent. For Solomon [15], congenital abnormalities of the urinary tract are the leading cause of chronic renal failure in children.

\section{Hypospadias}

Hypospadias is one of the most common congenital anomalies of the urethral spongiosum, the ventral prepuce and in more severe cases penile chordee. It is the most common urinary tract anomaly in our series with a mean age at the time of diagnosis of 67.2 months. While in developed countries, the average age at diagnosis varies from 16 to 24 months [16] [17] [18] [19]. This difference is related to several socio-cultural and economic factors in developing countries. Indeed, in developing countries, ignorance, poverty and traditional beliefs are diagnosis delay factors. The operative technique used was a function of the type of hypospadias and the habits of the surgeon. In clinical practice, many factors influence the choice of surgical technique, including "personal taste, upbringing, situation-al preference, training, experience and personal success" [20]. There are five sequential steps for the successful repair of hypospadias: penile straightening, urethroplasty, meatoplasty and glanuloplasty, scrotoplasty and skin cov- 
erage. The major technical advances in hypospadias surgery that have improved surgical outcomes are preservation of the urethral plate, incision of the urethral plate, dorsal midline plication, epithelized urethroplasty dartos flap coverage, and two stage alternative techniques [21]. Fistula is the most common complication after urethroplasty [22]; in our study, we noted $42.5 \%$ of fistula after uretrhoplasty.

\section{Posterior urethral valves}

During our study, we found 16 cases in 10 years, with a hospital frequency of 1.6 cases/years. They constitute the second cause of UTA with $20 \%$ of cases. The incidence of posterior urethral valves is variously reported in the literature ranging from 1 to $4 / 1000$ births [22] [23]. Urinary disorders such as dysuria or urine retention are constant [22] [23]. Ante-natal ultrasound allows the early management of this disease from birth [6]. Fogarty probe [24] is still the most commonly used technique in our hospital practice, although currently the standard treatment of the posterior urethral valves is endoscopic resection as soon as possible to avoid the occurrence complications [25] [26].

\section{Pyelo-ureteral junction syndrome}

In our series, it represents $7.6 \%$ of UTA; this rate is variable according to some authors, more important in developed countries especially in England with 38\% [27] and lower in developing countries with $14 \%$ in Tunisia [10] and $3.2 \%$ in Mali [28]. This difference can be explained by the absence or insufficiency of antenatal diagnosis and by low health coverage in our countries where the diagnosis is generally suspected during abdominal mass or complications including urinary infections. [10] [28]. In our series, treatment consisted of conventional pyeloplasty using the Anderson-Hynes technique [29] in 2 patients and the 3rd had a total nephrectomy due to destruction of the renal parenchyma.

Bladder exstrophy accounts for 5\% of UTA. This rate is identical to that found by N'diaye in Mali [30]. Initial treatment consisted of a plasty of the bladder, bladder neck, urethra and anterior abdominal wall associated with posterior iliac osteotomy; depending on the evolution, an enlargement can be proposed or a urinary derivation type Mitrofanoff [31].

Isolated epispadias with 3 cases remains a rare malformation; it was a penile continent epispadias in most cases and treated by urethroplasty [32].

Cystic dysplasia was diagnosed in 2 patients (2.5\%) and their management consisted of clinical and ultrasound surveillance as recommended in the literature [33].

\section{Conclusion}

Urinary tract anomalies are a group of relatively common diseases in children. In Congo, antenatal diagnosis is almost non-existent. This results in delay in management, the occurrence of complications, the most feared of which is renal failure. However, the majority of urinary tract anomalies consist of uncomplicated or less complicated forms with favorable prognosis and progression spontaneously or after surgical correction. 


\section{Conflicts of Interest}

The authors declare no conflicts of interest regarding the publication of this paper.

\section{References}

[1] Rousset-Rouvières, C. and Tsimaratos, M. (2010) Renal Malformations. EMC Pédiatrie. 4-088-C-10.

[2] Ouattara, K., Tembély, A. and Daffé, S. (1993) Renal Congenital Malformations and Obstructive Malfunctions of the High Excretory Pathway in Urology Practice in the Republic of Mali. Medicale d Afrique Noire, 40, 239-243.

[3] Cendron, J. and Faure, G. (2004) Congenital Diseases of the Kidney and Urinary Tract. Journal Urologie, 85-250.

[4] Kähler, J.U.C., Schulz, S., Mentzel, H.J., Vogt, S. and Misselwitz, J. (2004) The Impact of Fetal Renal Pelvic Diameter on Postnatal Outcomes. Prenatal Diagnosis, 24, 591-595. https://doi.org/10.1002/pd.899

[5] Podevin, G., Levard, G., Marechaud, M., Girault, F. and Barret, D. (1997) Postnatal Diagnostic Strategy of Malformative Uropathies Detected before Birth. Archives de Pédiatrie, 4, 411-415. https://doi.org/10.1016/S0929-693X(97)86663-8

[6] Asinobi, A.O., Gbadegesin, R.A. and Shittu, O.B. (2004) A Review of Cases Posterior Uréthral Valves Seen at the University College Hospital Ibadan, Nigeria, Pediatric. La Pediatria Medica e Chirurgica, 26, 430-433.

[7] Makosso, E. and Bouya, A.P. (2005) Diagnosis and Treatment of the Valves of the Posterior Urethra: About 3 Observations at the University Hospital of Brazzaville. Le Mali medical, 20, 5-7.

[8] Bouya, P.A. and Makosso, E. (2004) Diagnosis and Treatment of Pyelo-Ureteral Junction Syndrome: About 13 Cases. Journal Africain d' Imagérie Médicale, 1, 485-488.

[9] Keita, M., Diaouné, A., Diallo, A.F., Agbo, D., Keita, A., Magassouba, D.F. and Baldé, I. (2005) The Uropathy Malformations in Children at the University Hospital of Conakry about 50 Cases Collected from January 1995 to December 2000. Guinée Médicale, 3, 25-33.

[10] Kalhoul, N., Charfeddine, L., Fatnassi, R. and Amri, F. (2010) Malformative Uropathies in Children: About 71 Cases. Journal de Pédiatrie et de Puériculture, 23, 131-137. https://doi.org/10.1016/j.jpp.2009.10.004

[11] Tsai, J.D., Huang, F.Y., Lin, C.C., Tsai, T.C., Lee, H.C., Sheu, J.C. and Chang, P.Y. (2006) Intermittent Hydronephrosis Secondary to Urétéro-Pelvic Junction Obstruction; Clinical and Imaging Features. Pediatrics, 117, 139-146. https://doi.org/10.1542/peds.2005-0583

[12] John, U. (2004) The Impact of Fetal Renal Pelvic Diameter on Post-Natal Outcome. Prenatal Diagnosis, 24, 591-595. https://doi.org/10.1002/pd.899

[13] Grazina, K. (2006) Urological Anomalies in Children with Renal Agenesis or Multicystic Dysplasia. Journal of Applied Genetics, 47, 171-176. https://doi.org/10.1007/BF03194618

[14] Langer, B. (2003) Pyelectasis. Journal de Gynécologie Obstétrique et Biologie de la Reproduction, 32, 293-299.

[15] Salomon, R. (2005) Malformations de l'appareil urinaire: Facteurs pronostics à long terme. Journal de pédiatrie et de puériculture, 18, 310-313. https://doi.org/10.1016/j.jpp.2005.06.003

[16] Patel, R.P., Shulka, A.R. and Snyder, H.M. (2004) The Island Tube and Island Onlay 
Hypospadias Repairs Offer Excellent Long-Term Outcomes: A 14 Year Follow-up. Journal of Urology, 172, 171-179. https://doi.org/10.1097/01.ju.0000138903.20136.22

[17] Yucel, S., Sani, A., Karaguzel, G., Melikoglu, M. and Guntekin, E. (2006) Midline Dorsal Plication to Repair Recurrent Chordee at Reoperation for Hypospadias Surgery Complication. Journal of Urology, 175, 699-702. https://doi.org/10.1016/S0022-5347(05)00186-2

[18] Larrinaga, S.J., Oliver, L.F., Yanes, A.J.M., Camarra, Q.M., Gallego, S.J.A., Guisasola, Z.J. and Bernuy, M.C. (2000) Surgical Treatment of Hypospadias. Our Experience and Follow-up in 1993-1998. Archivos Españoles de Urología, 53, 155-158.

[19] Lam, P.N., Greenfield, S.P. and Williot, P. (2005) 2-Stage Repair in Infancy for Severe Hypospadias with Chordee: long-Term Results after Puberty. Journal of Urology, 174, 1567-1572. https://doi.org/10.1097/01.ju.0000179395.99944.48

[20] Baskin, L. (2010) Editorial Comment. Journal of Urology, 184, 1474-1475. https://doi.org/10.1016/j.juro.2010.06.151

[21] Baskin, L.S. and Ebbers, M.B. (2006) Hypospadias: Anatomy, Etiology, and Technique. Journal of Pediatric Surgery, 41, 463-472. https://doi.org/10.1016/j.jpedsurg.2005.11.059

[22] Snow, B.W., Cartwright, P.C. and Unger, K. (1995) Tunica Vaginalis Blanket Wrap to Prevent Urethrocutaneous Fistula: An 8-Year Experience. Journal of Urology, 153, 472-473. https://doi.org/10.1097/00005392-199502000-00061

[23] Workup (1992) Study of the Valves of the Posterior Urethra: About 35 Cases. Progrès en Urologie, 2, 861-73.

[24] Schober, J.M., Dulabon, L.M. and Woodhouse, C.R. (2004) Outcome of Valve Ablation in Late-Presenting Posterior Urethral Valves. BJU International, 94, 616-619. https://doi.org/10.1111/j.1464-410X.2004.05011.x

[25] Claude, B. (2001) Long-Term Results of Primary Avulsion of Posterior Urethral Valves with a Forgaty Probe. Journal of Urology, 90, 415-417.

[26] Warren, J. (2004) Posterior Urethral Valves in Eastern Ontario a 30 Year Perspective. Journal of Urology, 11, 2210-2215.

[27] Angwafo, F., Andzé, G., Biouelé, J.M., Sosso, M.A., Edzoa, T. and Niat, G. (1995) Valves of the Posterior Urethra in Children: About 22 Cases. Journal of Urology, 101, 132-137.

[28] Broadley, P. (1999) The 4 Years Outcome Following the Demonstration of Bilateral Renal Pelvic Dilatation on Pre-Natal Ultrasound. The British Journal of Radiology, 72, 265-270. https://doi.org/10.1259/bjr.72.855.10396216

[29] Kané, M., Keïta, A.D., Diallo, M., Coulibaly, T., Sidibé, S. and Traoré, I. (2006) Imaging Congenital Malformations of the Child's Urinary System: about 32 Cases. Mali Médical, 21, 5-9.

[30] Anderson, J.C. and Hynes, W. (1949) Retrocaval Ureter: A Case Diagnosed Peroperatively and Treated Successfully by Plastic Operation. British Journal of Urology, 21, 209-211. https://doi.org/10.1111/j.1464-410X.1949.tb10773.x

[31] N'diaye, D.D.D. (2000) Studies of Congenital Malformations at the University Hospital Gabriel TOURE. Medical Thesis, Mali, Bamako, No. 42.

[32] Brueziere, J., Audry, G. and Meria, P. (1992) Current Treatment of Bladder Extrophy. Annales d Urologie, 26, 293-295.

[33] Boillot, B., Téklali, Y., Moog, R. and Droupy, S. (2013) Penile Malformations. Progrès en Urologie, 23, 664-673. https://doi.org/10.1016/j.purol.2013.01.022 